\title{
Plackett-Burman Combined with Box-Behnken to Optimize the Medium of Fermented Tremella Polysaccharide and Compare the Characteristics before and after Optimization
}

\author{
Xia Ma $\mathbb{D},{ }^{1,2}$ Meng Yang $\left(\mathbb{D},{ }^{1}\right.$ Yan He $\mathbb{D},{ }^{1}$ Chenglinang $\mathrm{Li}\left(\mathbb{D},{ }^{3}\right.$ and Chuntao Zhai $\mathbb{D}^{3}$ \\ ${ }^{1}$ School of Perfume and Aroma Technology, Shanghai Institute of Technology, Shanghai 201418, China \\ ${ }^{2}$ State Key Laboratory of Dairy Biotechnology, Shanghai Engineering Research Center of Dairy Biotechnology, \\ Dairy Research Institute, Bright Dairy \& Food Co., Shanghai 200436, China \\ ${ }^{3}$ Laibo Pharmaceutical Technology (Shanghai) Co. Ltd., Shanghai 201418, China \\ Correspondence should be addressed to Chenglinang Li; richard-li@laibo.com.cn and Chuntao Zhai; ct-zhai@laibo.com.cn
}

Received 5 August 2020; Revised 11 November 2020; Accepted 6 December 2020; Published 21 December 2020

Academic Editor: Fatma M. El-Demerdash

Copyright ( $\odot 2020$ Xia Ma et al. This is an open access article distributed under the Creative Commons Attribution License, which permits unrestricted use, distribution, and reproduction in any medium, provided the original work is properly cited.

\begin{abstract}
The purpose of this study was to improve the yield of fermented Tremella polysaccharide (FTP) by optimizing the medium and to explore the effect of optimization on the structure. In this paper, the Plackett-Burman design and response surface method were used to optimize the fermentation medium of Tremella spore GT2\# for FTP production. The results of the Plackett-Burman design showed that potato extract, glucose, and peptone were the main factors. The Box-Behnken experiment and regression analysis determined that the optimal concentrations of potato extract, glucose, and peptone were $22.01 \%, 29.38 \mathrm{~g} / \mathrm{L}$, and $2.61 \mathrm{~g} / \mathrm{L}$, respectively. After optimization, the fermentation period shortened from 5 days to 3 days, and the yield of FTP increased from $10.75 \mathrm{~g} / \mathrm{L}$ to $12.50 \mathrm{~g} / \mathrm{L}$, which was in good agreement with the predicted value $(12.36 \mathrm{~g} / \mathrm{L})$. Characterization of FTP obtained before and after optimization was carried out, and the results showed that medium optimization had significant effects on the primary structure of FTP, including molecular weight, monosaccharide composition, and proportion. After optimization, the content of acid polysaccharide increased, and the glycoside bonds changed from $a$-configuration to $\beta$-configuration.
\end{abstract}

\section{Introduction}

Tremella polysaccharide (TP) is a kind of macromolecular substance with multiple biological activities. It is obtained from the fruit body, mycelia, or fermentation broth of Tremella fuciformis. TP has many physiological activities such as antiinflammatory [1], immune protection [2-4], antioxidation $[5,6]$, adjuvant treatment of diabetes [7], moisturizing [8], and gelation [9]. TP of high purity sells for up to $200000 \mathrm{RMB} / \mathrm{g}$. Commercially available TP is mainly obtained from the mature fruit body, but the quality and yield are easily affected by the environment [10]. High-density fermentation of Tremella fuciformis has many advantages such as easy control of the fermentation conditions, greatly increased yield, reduced production cycle [11], and meeting up with the market demand of fermented Tremella polysaccharides (FTPs).
At present, the research on Tremella polysaccharides by deep fermentation cannot be promoted on a large scale. The main reasons include large investment and low polysaccharide yield and purity. Therefore, related research has focused on the breeding of high-yielding Tremella spore polysaccharide strains and the optimization of fermentation conditions to increase the spore biomass and the production of exosporous polysaccharides. The yield of fermented Tremella polysaccharides has stabilized at about $4 \mathrm{~g} / \mathrm{L}$ in the past 10 years. In Dong's research [12], after 6 days of fermentation of Tremella spores, intracellular polysaccharides and extracellular polysaccharides were extracted at the same time, and the total yield reached $3.42 \mathrm{~g} / \mathrm{L}$. Zhu [13] controlled the $\mathrm{pH}$ of the fermentation environment and added different carbon sources to make the bacteria propagate rapidly, and the yield of Tremella polysaccharide reached 
$4.4 \mathrm{~g} / \mathrm{L}$ after $120 \mathrm{~h}$ fermentation, while fermentation of Tremella fuciformis spores by the method of controlling $\mathrm{pH}$ in three stages provided a polysaccharide yield of $3.8 \mathrm{~g} / \mathrm{L}$ [14]. Fermentation of Tremella mycelium has not yet been industrialized on a large scale because of the low yield and darker color of Tremella mycelium polysaccharides. Wang fermented the mycelium of Tremella fuciformis, and the concentration of acid Tremella fuciformis polysaccharide in the fermentation broth reached $1.9 \mathrm{~g} / \mathrm{L}$ [15].

According to previous studies, Tremella spore is more suitable for the deep fermentation to produce FTP than Tremella mycelium. Also, the integrated potato medium is a low-nitrogen [16], high-sugar [17], and highly inorganic salt [18] medium which is suitable for Tremella fuciformis fermentation [19]. Medium optimization will have a great impact on FTP output and product quality $[16,20,21]$. The optimization of the fermentation medium plays an important role in the industrial production of microorganisms, which is a necessary link from laboratory to industrial production. Whether a good fermentation medium can be designed is a very important step in the successful industrialization of fermentation products. In this study, Plackett-Burman and Box-Behnken response surface methods were used to optimize the fermentation medium. Factors affecting FTP yield were analyzed by glucose metabolism before and after optimization. The characterization differences of FTP before and after optimization were compared, and the effect of the optimized medium on the quality of polysaccharides from Tremella spores was evaluated. This paper will conduct an exploratory study on the influence of medium formulation on the structure of FTP. This research is expected to promote the industrialization of FTP.

\section{Materials and Methods}

2.1. Strain Culture. The Tremella fuciformis strain GT2\# used in this experiment was isolated from the laboratory of Shanghai Institute of Technology. The strain was inoculated at $28^{\circ} \mathrm{C}$ for $24 \mathrm{~h}$ in an integrated potato medium slant (glucose $20 \mathrm{~g} / \mathrm{L}$; potato extract $20 \%$, peptone $2 \mathrm{~g} / \mathrm{L}, \mathrm{KH}_{2} \mathrm{PO}_{4}$ $3 \mathrm{~g} / \mathrm{L}, \mathrm{MgSO}_{4} \cdot 7 \mathrm{H}_{2} \mathrm{O} 1.5 \mathrm{~g} / \mathrm{L}, \mathrm{Vb}_{1} 8 \mathrm{mg} / \mathrm{L}$, and agar $20 \mathrm{~g} / \mathrm{L}$ ) until the spores on the surface turned into a smooth round colony, and the slants were stored at $4^{\circ} \mathrm{C}$. All media were sterilized at $121^{\circ} \mathrm{C}$ for $20 \mathrm{~min}$.

2.2. Seed Preparation. The liquid seed medium formula is glucose $20 \mathrm{~g} / \mathrm{L}$, potato extract $20 \%$, peptone $2 \mathrm{~g} / \mathrm{L}, \mathrm{KH}_{2} \mathrm{PO}_{4} 3 \mathrm{~g} /$ $\mathrm{L}, \mathrm{MgSO}_{4} \cdot 7 \mathrm{H}_{2} \mathrm{O} 1.5 \mathrm{~g} / \mathrm{L}$, and $\mathrm{Vb}_{1} 8 \mathrm{mg} / \mathrm{L}$. The volume of seed liquid was $20 \%$ of the conical flask volume, and the culture conditions were as follows: $25{ }^{\circ} \mathrm{C}, 150 \mathrm{r} / \mathrm{min}$, and $24 \mathrm{~h}$. The optical density of spores was measured at $560 \mathrm{~nm}$ with 50 times diluted fermentation broth, and the seed preparation was completed when the absorbance reached 0.2.

2.3. Fermentation Culture. The fermentation medium is the same as the liquid seed medium, which is the integrated the potato medium. The inoculation dose was $2 \%$. The culture condition was $25^{\circ} \mathrm{C}, 250 \mathrm{r} / \mathrm{min}$, and the culture was carried out on a shaking table for 7 days. The fermentation broth was centrifuged at $10000 \times g$ for $15 \mathrm{~min}$. The supernatant was incubated to $100 \mathrm{~mL}$ with distilled water, and the total sugar content was measured and recorded as $T_{1}(\mathrm{~g} / \mathrm{L})$ and the reducing sugar content as $R_{1}(\mathrm{~g} / \mathrm{L})$. FTP yield records to $Y$ $(g / L)$ and calculated by equation (1). The utilization rate of reducing sugar is recorded as $\mathrm{U}(\%)$, which represents the substrate consumption, calculated by equation (2).

$$
\begin{aligned}
& Y(\mathrm{~g} / \mathrm{L})=T 1-R_{1}, \\
& U(\%)=\frac{(R 0-R 1)}{R 0} \times 100 \%,
\end{aligned}
$$

where $T_{1}(\mathrm{~g} / \mathrm{L})$ : total sugar content in the fermentation broth. $R_{1}$ (g/L): residual reducing sugar in the fermentation broth. $R_{0}(\mathrm{~g} / \mathrm{L})$ : initial reducing sugar content.

2.4. Single-Factor Experiments. Various factors (glucose, potato extract, peptone, $\mathrm{KH}_{2} \mathrm{PO}_{4}, \mathrm{MgSO}_{4} \cdot 7 \mathrm{H}_{2} \mathrm{O}$, and $V_{b 1}$ ) in the integrated potato medium were experimented at different concentrations. The optimal concentration range of each factor was preliminarily determined by the single-factor experiment. The experimental design is shown in Table 1.

2.5. Plackett-Burman Test. In order to rank the influence of various factors in the integrated potato medium on FTP yield, six independent variables at two levels with 15 runs were organized in accordance with the Plackett-Burman design. The low level $(-1)$ of the Plackett-Burman test was set as the optimal value of the single-factor experiment, and the high level $(+1)$ was about 1.25 times of the low level. The experimental level of each factor is shown in Table 2.

2.6. Steepest Ascent Experiment. According to the Plackett-Burman experiment, potato extract, glucose, and peptone were selected for the climbing experiment. The actual step size of potato extract was set to $1 \%$, and the actual step size of glucose and peptone is $-0.84 \mathrm{~g} / \mathrm{L}$ and $0.06 \mathrm{~g} / \mathrm{L}$, respectively.

2.7. Response Surface Methodology (RSM). The response surface methodology was used to optimize potato extract, glucose, and peptone further. As presented in Table 3, variables were designed as three-level (low, middle, and high) experiments and coded as $-1,0$, and 1 . According to the coding design, Design-Expert software generated a three-factor, three-level, 17-run experimental design scheme, using the yield of FTP $(Y)$ and the reducing sugar utilization $(U)$ rate as the response value at the end of fermentation. The interaction effect of variables on the bioresponse surface isogram was used to illustrate the interaction relationship between factors [19].

2.8. Regression Model Fitting and Variance Analysis. Design-Expert 7.0.1 software was used to output the results of variance analysis of the Plackett-Burman experiment and 
TABLE 1: Design of the single-factor experiment for a basic culture medium.

\begin{tabular}{lccccc}
\hline Trial run & 1 & 2 & 3 & 4 & 5 \\
\hline Potato extract $(\%)$ & 10.0 & 15.0 & 20.0 & 25.0 & 30.0 \\
Glucose $(\mathrm{g} / \mathrm{L})$ & 15.0 & 20.0 & 25.0 & 30.0 & 2.5 \\
Peptone $(\mathrm{g} / \mathrm{L})$ & 1.0 & 1.5 & 2.0 & 3.0 & 3.0 \\
$\mathrm{KH}_{2} \mathrm{PO}_{4}(\mathrm{~g} / \mathrm{L})$ & 2.0 & 2.5 & 1.5 & 4.0 \\
$\mathrm{MgSO}_{4} \cdot 7 \mathrm{H}_{2} \mathrm{O}(\mathrm{g} / \mathrm{L})$ & 0.5 & 1.0 & 8.0 & 2.0 & \\
$V_{b 1}(\mathrm{mg} / \mathrm{L})$ & 6.0 & 7.0 & & 9.0 & \\
\hline
\end{tabular}

TABle 2: Experimental level of the Plackett-Burman design.

\begin{tabular}{lcccc}
\hline Code & Factor & Units & Low level $(-1)$ & High level (1) \\
\hline A & Potato extract & $\%$ & 20.00 & 25.00 \\
B & Glucose & $\mathrm{g} / \mathrm{L}$ & 25.00 & 3.00 \\
$\mathrm{C}$ & $\mathrm{KH}_{2} \mathrm{PO}_{4}$ & $\mathrm{~g} / \mathrm{L}$ & 1.00 & 3.75 \\
$\mathrm{D}$ & $\mathrm{MgSO}_{4} \cdot 7 \mathrm{H}_{2} \mathrm{O}$ & $\mathrm{g} / \mathrm{L}$ & 7.00 & 1.90 \\
$\mathrm{E}$ & $V_{b 1}$ & $\mathrm{mg} / \mathrm{L}$ & 2.50 & 9.00 \\
$\mathrm{~F}$ & Peptone & $\mathrm{g} / \mathrm{L}$ & & 3.10 \\
\hline
\end{tabular}

TABLe 3: Factors and levels for the Box-Behnken design.

\begin{tabular}{lccccc}
\hline Factor & Name & Units & Low level $(-1)$ & Middle level $(0)$ & High level $(1)$ \\
\hline$A$ & Potato extract & $\%$ & 21.00 & 22.00 & 29.32 \\
$B$ & Glucose & g/L & 28.48 & 2.62 & 30.16 \\
$C$ & Peptone & g/L & 2.56 & 2.68 \\
\hline
\end{tabular}

Box-Behnken experiment and carry out regression analysis of the results of the Box-Behnken experiment to simulate the prediction equation.

2.9. Fermentation in a $5 \mathrm{~L}$ Fermentor. The results of medium optimization were verified in a $5 \mathrm{~L}$ stirred-tank reactor (sisobio-5l, Shanghai, China). Fermentation was carried out under the following conditions: temperature $25^{\circ} \mathrm{C}$, inflation rate $2 \mathrm{vvm}$, stirring speed $200 \mathrm{rpm}$, initial pH 7, working capacity 3 litres, and fermentation time 7 days.

In a fermentation cycle, $10 \mathrm{~mL}$ fermentation broth was taken every $24 \mathrm{~h}$ and centrifuged at $10000 \times g$ for $15 \mathrm{~min}$. The contents of reducing sugar and total sugar were determined, respectively, after the supernatant constant volumed to $10 \mathrm{~mL}$. The precipitate was washed 3 times, then freezedried, and recorded as the dry weight. The fermentation time was taken as the abscissa, and the reducing sugar content, total sugar content, and dry weight of the bacteria were used as the ordinates to draw the curves. The results were compared with the control group (before optimization).

2.10. Preparation and Extraction of FTP. Based on previous studies [22], freeze-thaw combined with the dual aqueous phase method was used to extract crude FTP from fermentation broth before and after optimization. The $10 \mathrm{mg} /$ $\mathrm{mL}$ crude FTP was eluted in a gradient on the DEAESepharose fast flow column. The eluent was $\mathrm{NaCl}$ solution with a concentration gradient of $0,0.2,0.4,0.6$, and $0.8 \mathrm{~mol} /$ L. The eluent flow rate was $1.5 \mathrm{~mL} / \mathrm{min}$. A total of 100 tubes were collected, each for 5 minutes. According to the total sugar content in the separated polysaccharide peaks, the recovery rate (equation (3)) of the purified fraction in the crude FTP and the proportion of FTP-1, FTP-2, and FTP-3 (equation (4)) in the purified fraction were calculated.

$$
\begin{array}{r}
\text { The recovery rate }(\%)=\frac{W 1}{W 0} \times 100 \%, \\
\text { Proportion }(\%)=\frac{T n}{W 1} \times 100 \%,
\end{array}
$$

where $W_{0}(\mathrm{mg})$ : weight of the crude FTP. $W_{1}(\mathrm{mg})$ : the sum of the weights of FTP-1, FTP-2, and FTP-3. $T_{\mathrm{n}}(\mathrm{mg})$ : total sugar content in FTP-n $(n=1,2,3)$.

2.11. Determination of Polysaccharides, Reducing Sugar, and Protein Content. The total sugar in fermentation broth was determined by the phenol-sulfuric acid method [23]. The reducing sugar in fermentation broth was determined by the DNS method [24]. The protein content was measured using the Bradford method with bovine serum albumin as a standard [25].

2.12. Infrared Analysis. The FTP was determined by infrared spectroscopy with the $\mathrm{KBr}$ tablet pressing method. The blank $\mathrm{KBr}$ tablets were used as the control group and scanned in the range of $4000-400 \mathrm{~cm}^{-1}$ [26]. The spectral resolution is $4 \mathrm{~cm}^{-1}$. 
2.13. Molecular Weight Determination. The molecular weight of FTP $(0.2 \mathrm{mg} / \mathrm{mL})$ was determined by high-performance size exclusion chromatography (HPSEC) [27]. The chromatographic column was a Waters Ultrahydrogel TM linear $(7.8 \times 300 \mathrm{~mm}, 10 \mu \mathrm{m})$ gel column, the mobile phase was $0.1 \mathrm{~mol} / \mathrm{L} \mathrm{NaNO}_{3}$, the flow rate was $0.9 \mathrm{~mL} / \mathrm{min}$, the column temperature was $45^{\circ} \mathrm{C}$, and the loading volume was $20 \mu \mathrm{L}$.

\subsection{Monosaccharide Composition Analysis. HPAEC-PAD} (high-performance anion-exchange pulsed amperometric detection chromatography) [28] was performed to determine the monosaccharide composition and the molar ratio of FTP before and after optimization.

Sample hydrolysis: $5 \mathrm{mg} / \mathrm{mL}$ FTP $(100 \mu \mathrm{L})$ was hydrolyzed with $4 \mathrm{~mol} / \mathrm{L}$ trifluoroacetic acid $(100 \mu \mathrm{L})$ at $110^{\circ} \mathrm{C}$ for $2 \mathrm{~h}$. Trifluoroacetic acid was rinsed with methanol $(200 \mu \mathrm{L})$, and residual methanol was rinsed with nitrogen. The residue was dissolved to $5 \mathrm{~mL}$ for sample analysis by ion chromatography (Waters600 liquid chromatograph, Waters, United States).

Chromatographic conditions: Dionex ICS5000 system; column: CarboPac PA20 (ID $3 \times 150 \mathrm{~mm}$ ); mobile phase: A, $\mathrm{H}_{2} \mathrm{O} ; \mathrm{B}, 250 \mathrm{mmol} / \mathrm{L} \mathrm{NaOH}$; and C, $1 \mathrm{~mol} / \mathrm{L} \mathrm{NaAc}$, ternary gradient elution; flow rate: $0.5 \mathrm{~mL} / \mathrm{min}$; pulsed amperometric detector (PAD); $\mathrm{Au}$ working electrode; $\mathrm{Ag} / \mathrm{AgCl}$ reference electrode; injection volume: $20 \mu \mathrm{L}$; and column temperature: $30^{\circ} \mathrm{C}$.

2.15. Data Analysis. All experiments in this study were conducted in triplicates, and the data were presented as mean. Differences between groups were assessed using a $t$ test. A $P$ value less than 0.05 was considered statistically significant.

\section{Results and Discussion}

3.1. Single-Factor Experiments. The results (Figure 1) of the single-factor experiment have shown that the optimum range of components of the FTP medium should be as follows: potato extract $20 \%$, glucose $25.0 \mathrm{~g} / \mathrm{L}$, peptone $2.5 \mathrm{~g} /$ $\mathrm{L}, \mathrm{KH}_{2} \mathrm{PO}_{4} 3.0 \mathrm{~g} / \mathrm{L}, \mathrm{MgSO}_{4} \cdot 7 \mathrm{H}_{2} \mathrm{O} 1.5 \mathrm{~g} / \mathrm{L}$, peptone $2.5 \mathrm{~g} / \mathrm{L}$, and $V_{b 1} 7.0 \mathrm{mg} / \mathrm{L}$.

3.2. Plackett-Burman Test. The design and results of the Plackett-Burman experiment are shown in Table 4. The variance analysis of Plackett-Burman experimental results in Table 5 proves the reliability of the experimental results. The Plackett-Burman experimental model is significant $(p<0.0001)$, and the missing item is not significant $(p=0.3437)$, indicating that the measured and predicted values of FTP have a good fitting degree and can truly reflect the experimental results. Potato extract $(p<0.0001)$, glucose $(p<0.0001)$, and peptone $(p=0.0005)$ have significant effects on the yield of FTP. Figure 2 also implies that potato extract, glucose, and peptone have significant effects on FTP yield, and the influence degree of each factor is ranked. The order of effects from high to low was as follows: potato extract, glucose, peptone, $\mathrm{KH}_{2} \mathrm{PO}_{4}, V_{b 1}$, and $\mathrm{MgSO}_{4} \cdot 7 \mathrm{H}_{2} \mathrm{O}$. Therefore, potato extract (A), glucose (B), and peptone (F) should be selected as the main factors for the steepest ascent experiment. Among them, potato extract (A) and peptone (F) have negative effects on FTP yield, which means that the following optimization should start from the low level of the Plackett-Burman experiment. Glucose (B) has a positive effect on the output of FTP, which means that the higher the glucose content is, the more conducive it is to the production of FTP, and the follow-up optimization should start from the high level of the Plackett-Burman experimental design.

According to the results of the Plackett-Burman experiment, Design-Expert 7.0.1 also outputs the prediction equation of FTP yield.

$$
Y(\text { yield of FTP, g/L })=5.11-2.7 A+1.89 B-1.32 F,
$$

where A: potato extract, \%; B: glucose, g/L; and F: peptone, g/ L.

In equation (5), corresponding to Figure 2, the coefficient of the independent variable represents its effect on the output of FTP. The positive coefficient of the independent variable indicated that the factor is not a risk factor, and the higher factor value would more easily promote the production of FTP. The coefficients of the factors determine the direction of the optimal pathways. According to the abovementioned results, the initial value of the climbing experiment should be set as potato extract (20\%), glucose $(31 \mathrm{~g} / \mathrm{L})$, and peptone $(2.5 \mathrm{~g} / \mathrm{L})$.

3.3. Steepest Ascent Experiment. The experimental design and results are shown in Table 6 . It is apparent that the yield of FTP showed a peak value when the concentrations of potato extract, glucose, and peptone were $22 \%, 29.32 \mathrm{~g} / \mathrm{L}$, and $2.68 \mathrm{~g} / \mathrm{L}$, respectively. At this point, the yield of FTP was close to the maximum reaction zone, so the data set was selected as the central value of the response surface optimization design.

3.4. Box-Behnken Design. The RSM design and results are recorded in Table 7 . Figure 3 shows the interaction between the various factors in the medium when the yield of FTP and glucose utilization are, respectively, used as responses through contour plots.

The effects on FTP production of changes in the concentration of potato extract and glucose are shown in Figure 3(a). High FTP production was recorded when the concentration of potato extract and glucose was from $21.5 \%$ to $22.5 \%$ and $28.4 \mathrm{~g} / \mathrm{L}$ to $29.74 \mathrm{~g} / \mathrm{L}$, respectively. Similarly, from the contour plot (Figure 3(b)), it can be seen that potato extract and peptone approximately yield FTP between $22 \%$ and $23 \%$ and $2.56 \mathrm{~g} / \mathrm{L}$ and $2.65 \mathrm{~g} / \mathrm{L}$, respectively. In the contour plot (Figure $3(\mathrm{c})$ ), FTP production has a simultaneous optimal region in the concentrations of glucose and peptone from $28.48 \mathrm{~g} / \mathrm{L}$ to $29.32 \mathrm{~g} / \mathrm{L}$ and $2.56 \mathrm{~g} / \mathrm{L}$ to $2.65 \mathrm{~g} / \mathrm{L}$, respectively. 


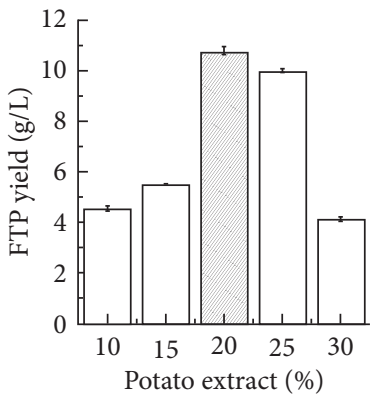

(a)

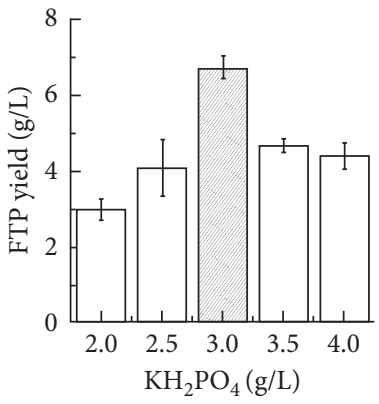

(d)

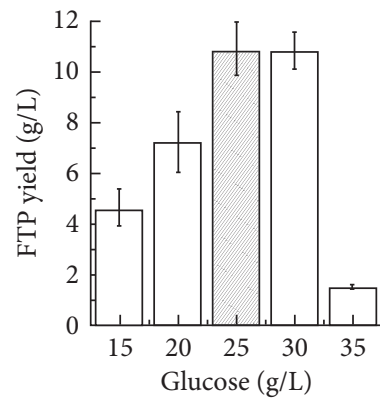

(b)

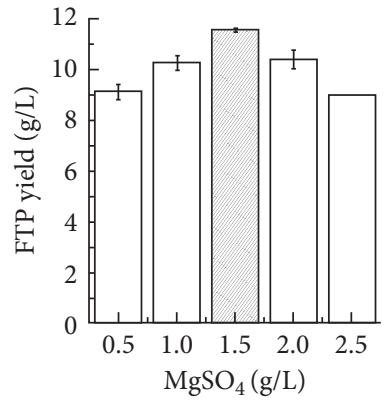

(e)

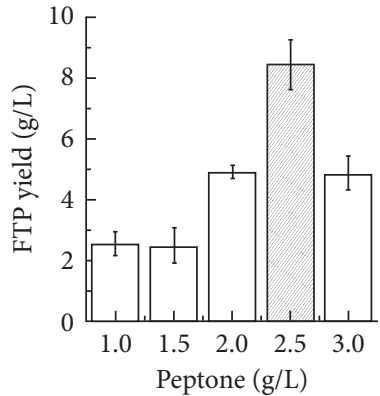

(c)

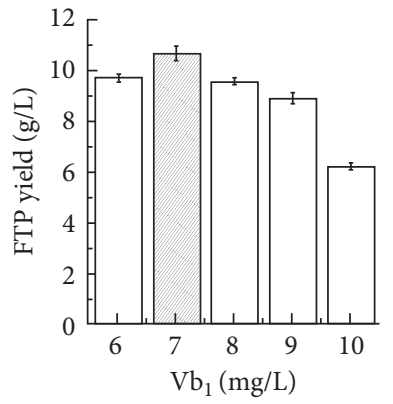

(f)

Figure 1: The bar graph of each single factor in the basic fermentation medium.

TABLE 4: Experimental design and results of the Plackett-Burman experiment.

\begin{tabular}{|c|c|c|c|c|c|c|c|}
\hline Trial run & Potato extract (\%) & Glucose $(\mathrm{g} / \mathrm{L})$ & $\mathrm{KH}_{2} \mathrm{PO}_{4}(\mathrm{~g} / \mathrm{L})$ & $\mathrm{MgSO}_{4} \cdot 7 \mathrm{H}_{2} \mathrm{O}(\mathrm{g} / \mathrm{L})$ & $V_{b 1}(\mathrm{mg} / \mathrm{L})$ & Peptone (g/L) & $Y(\mathrm{~g} / \mathrm{L})$ \\
\hline 1 & -1 & 1 & 1 & -1 & 1 & 1 & 8.28 \\
\hline 2 & 1 & 1 & -1 & 1 & 1 & 1 & 3.03 \\
\hline 3 & 0 & 0 & 0 & 0 & 0 & 0 & 4.71 \\
\hline 4 & 1 & 1 & 1 & -1 & -1 & -1 & 4.51 \\
\hline 5 & 1 & -1 & 1 & 1 & 1 & -1 & 1.87 \\
\hline 6 & -1 & -1 & 1 & -1 & 1 & 1 & 3.35 \\
\hline 7 & 0 & 0 & 0 & 0 & 0 & 0 & 5.91 \\
\hline 8 & -1 & 1 & -1 & 1 & 1 & -1 & 11.42 \\
\hline 9 & 0 & 0 & 0 & 0 & 0 & 0 & 4.91 \\
\hline 10 & 1 & -1 & 1 & 1 & -1 & 1 & 0.05 \\
\hline 11 & -1 & 1 & 1 & 1 & -1 & -1 & 10.94 \\
\hline 12 & -1 & -1 & -1 & -1 & -1 & -1 & 8.75 \\
\hline 13 & 1 & -1 & -1 & -1 & 1 & -1 & 1.15 \\
\hline 14 & 1 & 1 & -1 & -1 & -1 & 1 & 3.87 \\
\hline 15 & -1 & -1 & -1 & 1 & -1 & 1 & 4.17 \\
\hline
\end{tabular}

TABle 5: Variance analysis results of the Plackett-Burman experiment.

\begin{tabular}{lccccc}
\hline Source & Sum of squares & $\mathrm{df}$ & Mean square & F value & $p$ value prob $>F$ \\
\hline Model & 151.6 & 3 & 50.53 & 61.19 & $<0.0001$ \\
A- potato extract & 87.62 & 1 & 87.62 & 106.1 & $<0.0001$ \\
B- glucose & 42.94 & 1 & 42.94 & 52 & $<0.0001$ \\
F- peptone & 21.04 & 1 & 21.04 & 25.47 & 0.0005 \\
Curvature & $9.68 \times 10^{-3}$ & 1 & $9.68 \times 10^{-3}$ & 0.012 & 0.9159 \\
Residual & 8.26 & 10 & 0.83 & & 0.3437 \\
Lack of fit & 7.43 & 8 & 0.93 & 2.25 & Not significant \\
Pure error & 0.83 & 2 & 0.41 & & Not significant \\
Cor total & 159.86 & 14 & & & \\
\hline
\end{tabular}




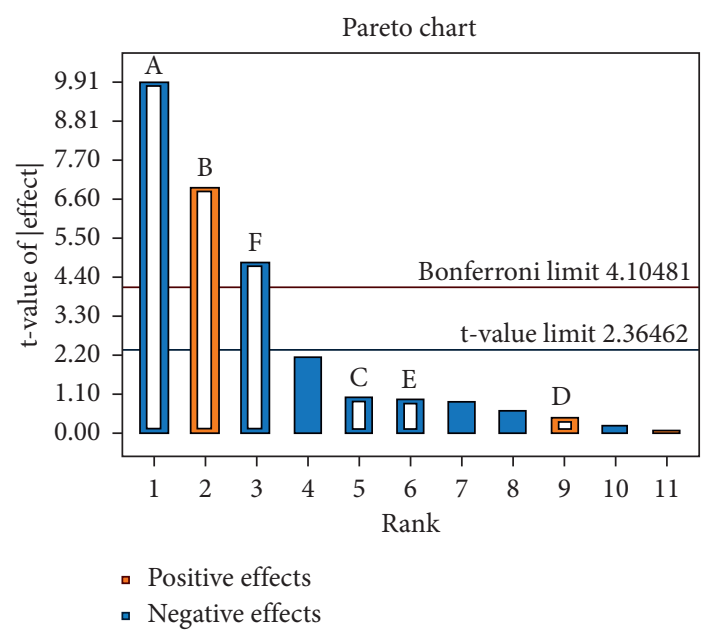

Figure 2: Pareto chart of the Plackett-Burman design for the FTP yield. (A) Potato extract, (B) glucose, (C) $\mathrm{KH}_{2} \mathrm{PO}_{4}$, (D) $\mathrm{MgSO}_{4} \cdot 7 \mathrm{H}_{2} \mathrm{O}$, (E) $V_{b 1}$, and (F) peptone.

TABLE 6: Design and results of the steepest ascent experiment.

\begin{tabular}{lccccc}
\hline Test no. & 1 & 2 & 3 & 4 & 5 \\
\hline Potato extract(\%) & 20.00 & 21.00 & 22.00 & 23.00 & 24.00 \\
Glucose(g/L) & 31.00 & 30.16 & 29.32 & 2.48 & 2.68 \\
Peptone(g/L) & 2.50 & 12.56 & 13.92 & 11.54 & 2.74 \\
Yield(g/L) & 12.05 & 12.60 & & 11.48 \\
\hline
\end{tabular}

TABLE 7: Experimental design and results of Box-Behnken.

\begin{tabular}{|c|c|c|c|c|c|}
\hline Trial run & Potato extract & Glucose & Peptone & $Y(\mathrm{~g} / \mathrm{L})$ & $U(\mathrm{~g} / \mathrm{L})$ \\
\hline 1 & 0 & 1 & -1 & 11.83 & 86.88 \\
\hline 2 & 1 & -1 & 0 & 12.23 & 81.53 \\
\hline 3 & 1 & 0 & 1 & 11.59 & 88.63 \\
\hline 4 & 1 & 0 & -1 & 12.14 & 82.75 \\
\hline 5 & 0 & 0 & 0 & 12.20 & 79.28 \\
\hline 6 & -1 & -1 & 0 & 11.86 & 83.88 \\
\hline 7 & 0 & 0 & 0 & 12.44 & 77.30 \\
\hline 8 & 0 & 0 & 0 & 12.36 & 76.90 \\
\hline 9 & -1 & 0 & -1 & 11.57 & 89.29 \\
\hline 10 & -1 & 0 & 1 & 11.40 & 85.72 \\
\hline 11 & 0 & -1 & -1 & 12.41 & 79.37 \\
\hline 12 & -1 & 1 & 0 & 10.68 & 87.38 \\
\hline 13 & 1 & 1 & 0 & 12.00 & 84.20 \\
\hline 14 & 0 & 1 & 1 & 11.40 & 82.77 \\
\hline 15 & 0 & 0 & 0 & 12.42 & 76.74 \\
\hline 16 & 0 & 0 & 0 & 12.35 & 77.98 \\
\hline 17 & 0 & -1 & 1 & 12.04 & 80.04 \\
\hline
\end{tabular}

As shown in Figure 3, the effect of factors on glucose utilization was complex. When the concentration of potato extract was in the range of $21 \% \sim 21.75 \%$ and glucose was in the range of $29 \mathrm{~g} / \mathrm{L} \sim 30 \mathrm{~g} / \mathrm{L}$, an increase in the glucose utilization ratio was observed in Figure $3(\mathrm{~d})$. Also, potato extract and peptone approach the maximum reaction center of glucose utilization between $21 \% \sim 22 \%$ and $2.56 \mathrm{~g} / \mathrm{L}$ to $2.65 \mathrm{~g} / \mathrm{L}$, respectively (Figure 3(e)). In the contour plot (Figure $3(\mathrm{f})$ ), the glucose utilization ratio has an optimal region in the concentrations of glucose and peptone from $29 \mathrm{~g} / \mathrm{L}$ to $30 \mathrm{~g} / \mathrm{L}$ and $2.56 \mathrm{~g} / \mathrm{L}$ to $2.65 \mathrm{~g} / \mathrm{L}$, respectively.

3.5. Regression Model Fitting and Variance Analysis. As shown in Table 8, when the yield of FTP and glucose utilization were used as the response values, the probability of the regression model $>F$ value was 0.0004 and 0.0027 , respectively. The results indicated that this model could 


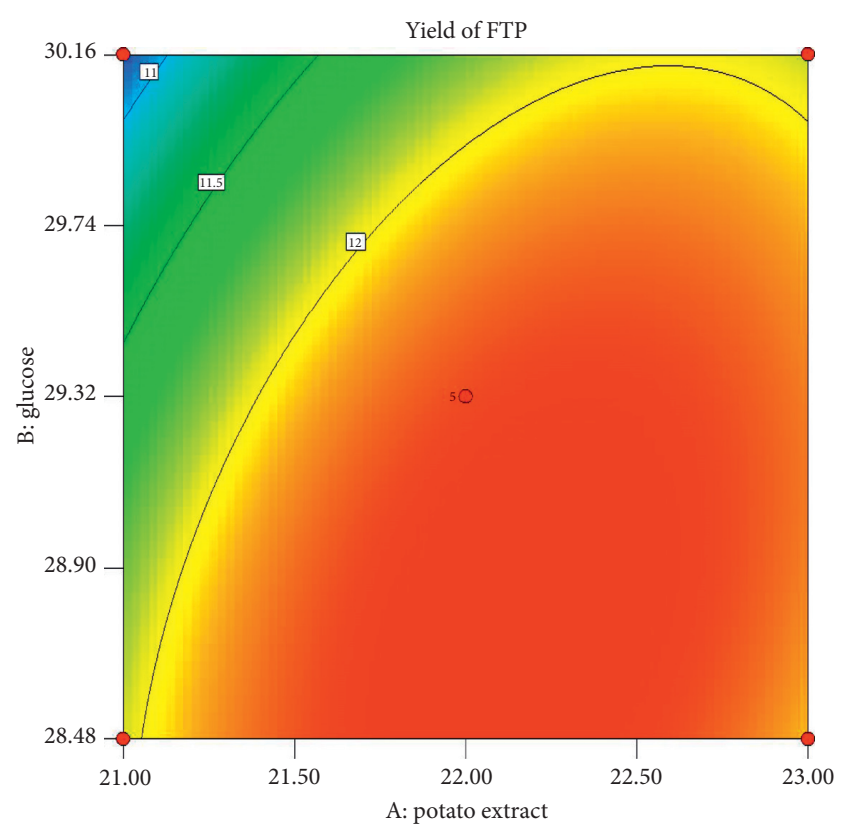

(a)

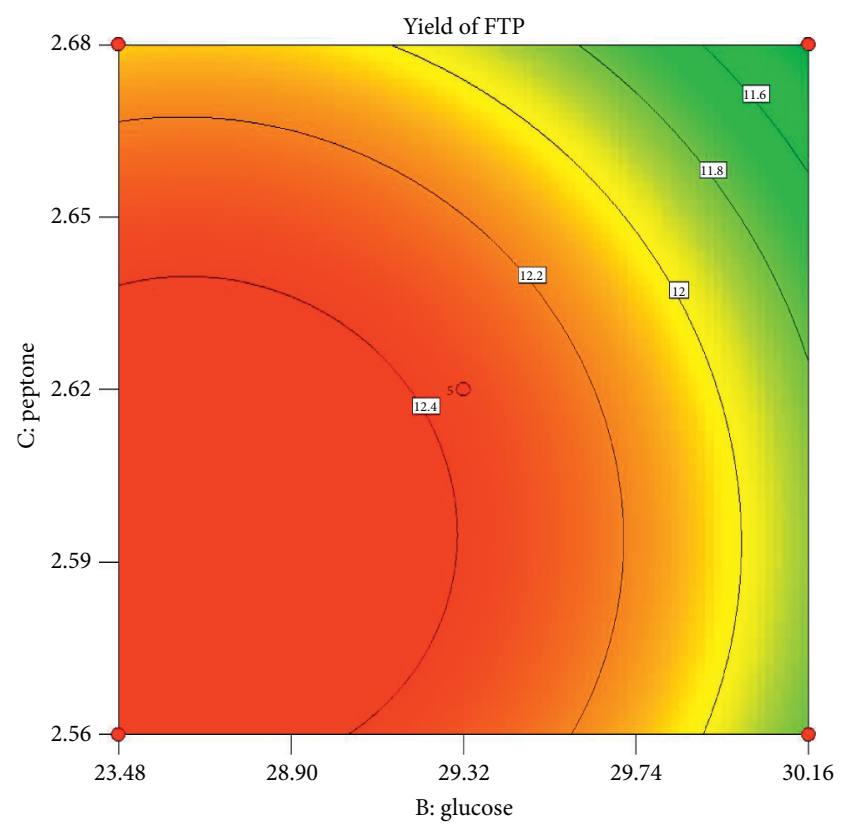

(c)

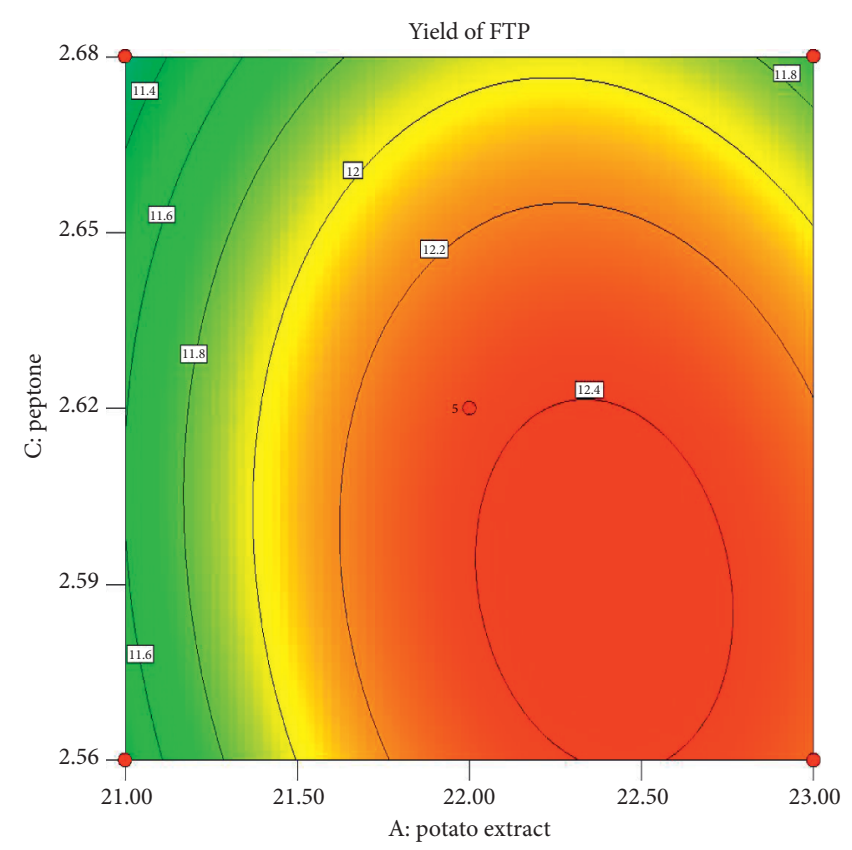

(b)

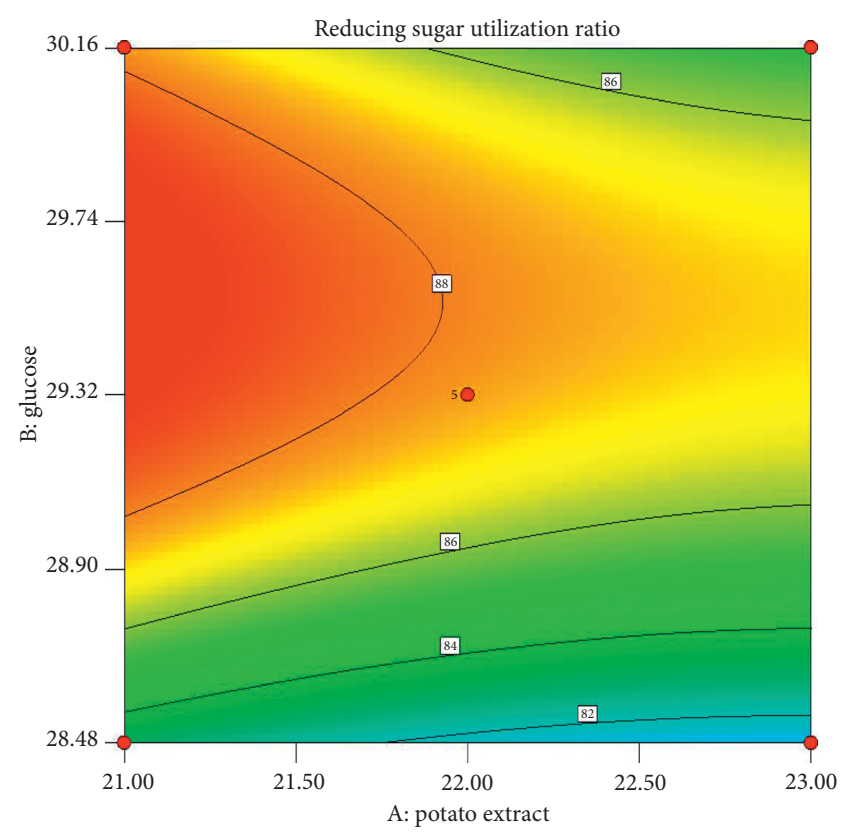

(d)

Figure 3: Continued. 


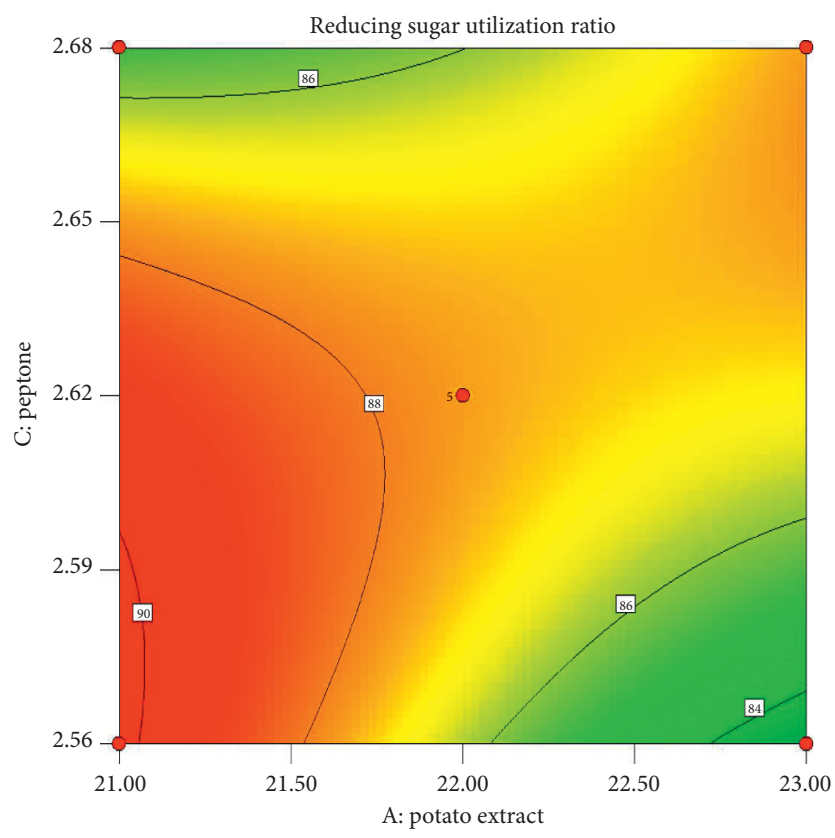

(e)

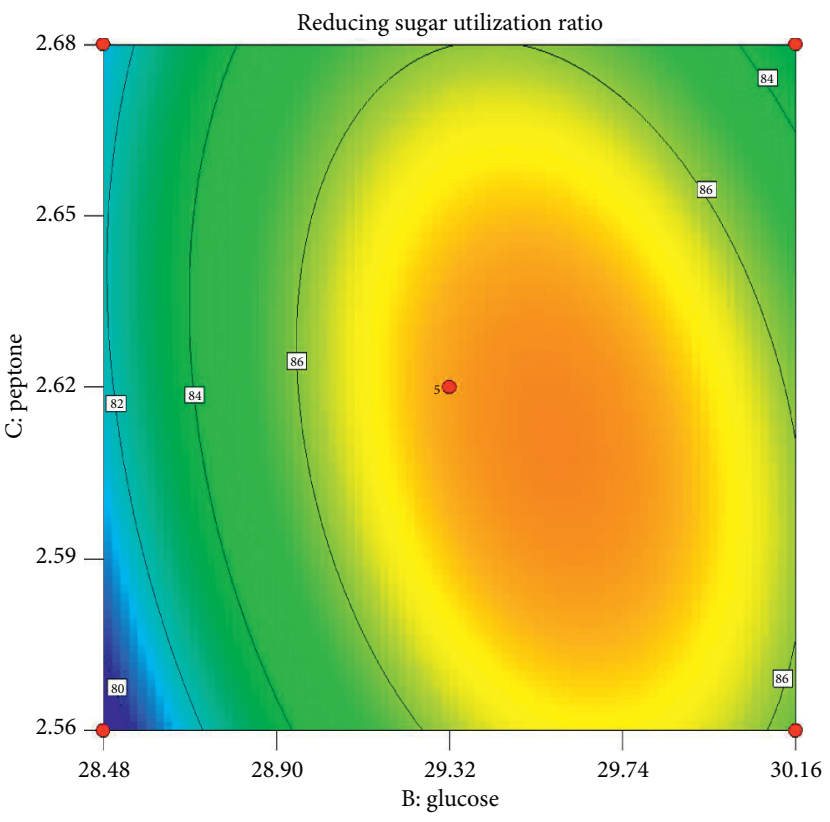

(f)

FIGURE 3: (a c) Contour plots of yield of FTP showing interactions between potato extract and glucose (a), potato extract and peptone (b), and glucose and peptone $(\mathrm{c}) .(\mathrm{d} \sim \mathrm{f})$ The interaction effect of variables on reducing the glucose utilization ratio.

TABLE 8: ANOVA for the response surface polynomial model of all independent variables.

\begin{tabular}{|c|c|c|c|c|c|c|}
\hline \multirow{2}{*}{ Factor } & \multicolumn{3}{|c|}{ FTP yield (Y) } & \multicolumn{3}{|c|}{ Glucose utilization ratio $(\mathrm{U})$} \\
\hline & SS & $\mathrm{F}$ value & Prob $>F$ & SS & $\mathrm{F}$ value & Prob $>F$ \\
\hline Model & 3.55 & 18.42 & 0.0004 & 147.8 & 10.49 & 0.0027 \\
\hline A- potato ex. & 0.75 & 35.22 & 0.0006 & 10.51 & 6.72 & 0.0359 \\
\hline B- glucose & 0.86 & 40.21 & 0.0004 & 33.59 & 21.47 & 0.0024 \\
\hline C- peptone & 0.29 & 13.57 & 0.0078 & 0.17 & 0.11 & 0.7537 \\
\hline $\mathrm{AB}$ & 0.22 & 10.43 & 0.0145 & 0.17 & 0.11 & 0.7492 \\
\hline $\mathrm{AC}$ & 0.036 & 1.67 & 0.2377 & 22.3 & 14.25 & 0.0069 \\
\hline $\mathrm{BC}$ & $8.04 \times 10^{-4}$ & 0.038 & 0.8519 & 5.72 & 3.65 & 0.0976 \\
\hline $\mathrm{A}^{2}$ & 0.86 & 40.33 & 0.0004 & 0.93 & 0.59 & 0.4666 \\
\hline $\mathrm{B}^{2}$ & 0.18 & 8.52 & 0.0224 & 62.83 & 40.15 & 0.0004 \\
\hline$C^{2}$ & 0.22 & 10.12 & 0.0155 & 9.6 & 6.13 & 0.0424 \\
\hline Residual & 0.15 & & & 10.95 & & \\
\hline Lack of fit & 0.11 & 4.11 & 0.1027 & 6.68 & 2.08 & 0.2452 \\
\hline Pure error & $3.70 \times 10^{-2}$ & & & 4.28 & & \\
\hline
\end{tabular}

predict the FTP yield and the utilization rate of reducing sugar reliably. The model prediction equations are given as follows:

$$
\begin{aligned}
Y= & 12.35+0.31 \times A-0.33 \times B-0.19 \times C+0.24 \times A \times B-0.094 \times A \times C-0.014 \\
& \times B \times C-0.45 \times A 2-0.21 \times B 2-0.23 \times C 2, \\
U= & 87.64-1.15 \times A+2.05 \times B-0.14 \times C-0.21 \times A \times B+2.36 \times A \times C-1.20 \times B \\
& \times C+0.47 \times A 2-3.86 \times B 2-1.51 \times C 2,
\end{aligned}
$$


where $\mathrm{Y}$ is the FTP yield and $\mathrm{U}$ is the glucose utilization ratio and $A, B$, and $C$ are the coded values of potato extract, glucose, and peptone, respectively.

When $Y$ and $U$ are at their maximum, the concentrations of $A, B$, and $C$ are the optimal concentrations of the medium.
When the $p$ value is greater than 0.1 , it is an insignificant factor (Table 8). After removing the insignificant factors, the following equations are obtained:

$$
\begin{aligned}
& Y=12.35+0.31 \times A-0.33 \times B-0.19 \times C+0.24 \times A \times B-0.45 \times A 2-0.21 \times B 2-0.23 \times C 2, \\
& U=87.64-1.15 \times A+2.05 \times B+2.36 \times A \times C-1.20 \times B \times C-3.86 \times B 2-1.51 \times C 2 .
\end{aligned}
$$

The optimal predicted value can be obtained from equations (8) and (9). When the reducing sugar utilization rate $(87.73 \%)$ and the yield of FTP $(12.36 \mathrm{~g} / \mathrm{L})$ reached the maximum at the same time, the concentration of potato extract $(\mathrm{A} / 22.01 \%)$, glucose $(\mathrm{B} / 29.38 \mathrm{~g} / \mathrm{L})$, and peptone $(\mathrm{C} /$ $2.61 \mathrm{~g} / \mathrm{L})$ was the optimal combination.

3.6. Production of Crude FTP in a 5 L Fermentor. The results of the scale-up fermentation experiments are presented in Figure 4 . The maximum biomass of the optimized medium reached $1.52 \mathrm{~g} / \mathrm{L}$, which was $0.61 \%$ lower than that of the control group. However, the FTP production increased from $10.75 \mathrm{~g} / \mathrm{L}$ to $12.50 \mathrm{~g} / \mathrm{L}$ after $72 \mathrm{~h}$ of fermentation, which was $116.27 \%$ higher than the control. Moreover, the yield of FTP $(12.50 \mathrm{~g} / \mathrm{L})$ was consistent with the predicted value of $12.36 \mathrm{~g} / \mathrm{L}$. Furthermore, the fermentation cycle was significantly shorter than before optimization. The optimized group ushered in an important turning point after fermented for three days. At this point, the consumption rate of reducing sugar began to decline (Figure 4(a)), FTP accumulated rapidly (Figure 4(b)), and GT2\# multiplied rapidly (Figure 4(c)); all of these phenomena indicated that Tremella spores grow and metabolize very vigorously on the third day of fermentation. After the medium was optimized, the fermentation was finished on the third day, two days earlier than the control, which shortened the fermentation cycle greatly.

3.7. Purification of FTP. The results of homogeneous polysaccharide components obtained from the purification of crude FTP are shown in Figure 5. The crude FTP contains three components, among which the neutral polysaccharide components eluted by distilled water were in tubes 15 22, the weakly acidic polysaccharide components were in tubes 37 50, and the acidic polysaccharide components were collected in tubes 58 75, which are recorded as FTP-1, FTP2, and FTP-3 in turn (Figure 5(a)). The optimized FTP peak position shifted slightly to the left, indicating that the proportion of neutral polysaccharide increased. In addition, the three peaks of the optimization group were all symmetrical single peaks with obvious boundaries, indicating that the separation effect was significantly higher than that of the control group.

As shown in Figure 5(b), the total sugar content of FTP1, FTP-2, and FTP-3 only accounts for $84.69 \%$ of the total mass of the purified FTP components, indicating that the control group has many impurities and contains components that are difficult to be separated. After optimization, the FTP recovery rate was $30.07 \%$, which is $21 \%$ higher than that of the control group (24.78\%). Among them, the proportion of acid polysaccharide components was $66.18 \%$, which was 1.17 times higher than that before optimization (56.46\%). Current studies have shown that acidic polysaccharides are the main active components of FTP. Even in the optimized medium, the content of acid polysaccharide produced by Tremella spores was still lower than that of mycelia (75.32\%) and frustums (94.66\%) [15]. However, the total output $(8.19 \mathrm{~g} / \mathrm{L})$ can make up for its deficiency in content, so it is feasible to produce highly active FTP using the optimized medium.

3.8. Total Sugar and Protein Content Change. The total sugar and protein contents of FTP-3 before and after optimization are summarized in Figure 6. After optimization, the protein decreased and the total sugar increased. Therefore, the optimization had a high production of total sugar, and the purification efficiency can be improved by reducing protein production.

3.9. Effect of Medium Optimization on $M_{w}$. The $M_{\mathrm{W}}$ of the FTP before and after optimization was measured (Table 9). The size and distribution of the molecular weight of FTP in the optimized group changed. $M_{w}$ and $M_{n}$ increased to some extent. The parameter $\mathrm{M}_{\mathrm{w}} / \mathrm{M}_{\mathrm{n}}$ indicates the distribution range of the molecular weight of the sample, while $M_{w} / M_{n}$ of the optimized group becomes smaller, indicating that the molecular weight range of FTP in the optimized group is narrower, that is, it has better uniformity. The parameter (\%/area) indicates that the FTP in the control group contains impurities of different molecular weights, which may be caused by the protein $(7.20 \pm 0.27 \%)$ it contains (Figure 6). However, the protein content in the optimized group was very small $(1.17 \pm 0.15 \%)$, so the molecular weight distribution was not affected obviously (Figure 6). The molecular weight of FTP obtained by submerged fermentation is much smaller than that of the polysaccharides of Tremella fruit bodies reported in the literature $(7.8 \times 105)$ [29]. Small molecules of Tremella polysaccharides can play a more important role in drug delivery systems. 


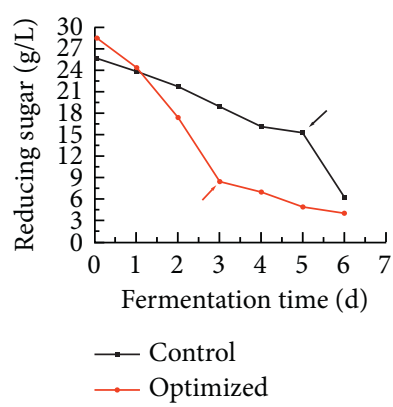

(a)

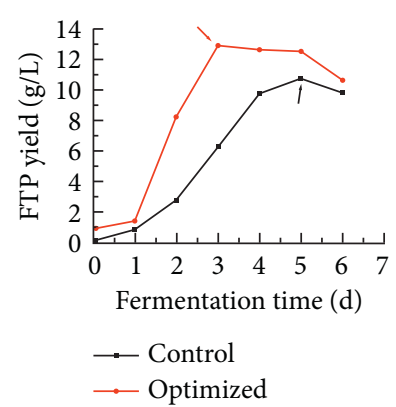

(b)

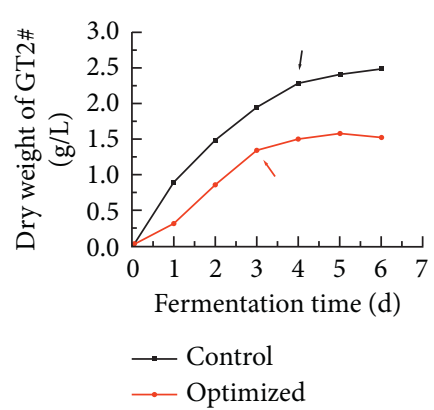

(c)

FIGURE 4: Comparison of fermentation in an optimized and preoptimized medium in a $5 \mathrm{~L}$ fermentor. (a) RG (reducing sugar), (b) FTP yield, and (c) dry weight of GT2\#.

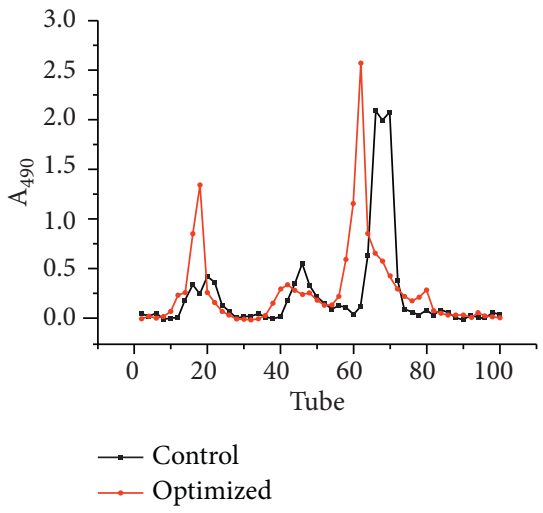

(a)

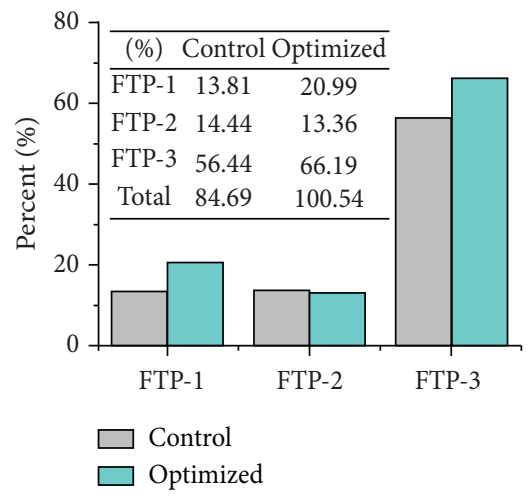

(b)

Figure 5: Isolation and purification of crude FTP. (a) The DEAE-Sepharose fast flow ion exchange chromatography elution curve for FTP in the control and optimized group. (b) The proportion of FTP-1, FTP-2, and FTP-3 in all purified components.

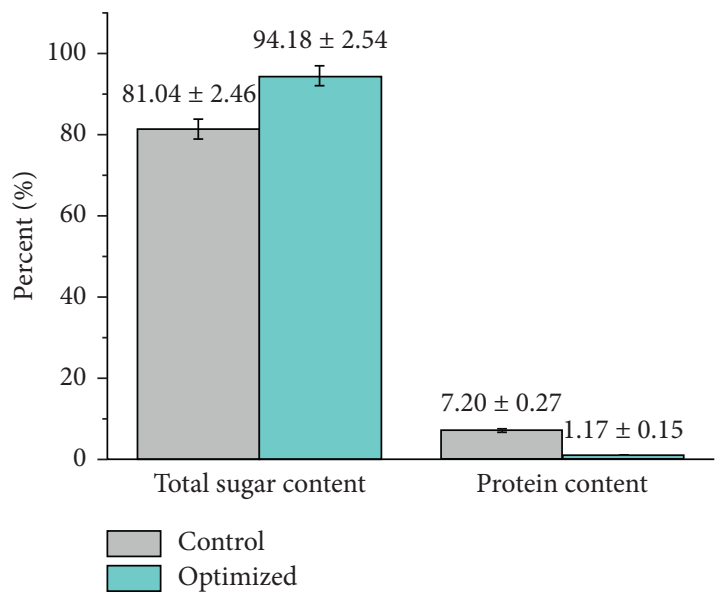

Figure 6: The change of total sugar content and protein content.

3.10. Infrared Spectrum Analysis. Infrared spectra showed that FTPs in the control and optimized group had a similar structure except for the peak at $850 \mathrm{~cm}^{-1}$ (Figure 7). The optimization group is taken as an example to illustrate the analytical infrared spectrum. A strong and wide absorption peak at $3700-3000 \mathrm{~cm}^{-1}$ indicates the
TABle 9: Molecular weight.

\begin{tabular}{lcccc}
\hline Sample & $M_{w}$ & $M_{n}$ & $M_{w} / M_{n}$ & \%/area \\
\hline Control & 16236 & 9760 & 1.66 & 94.99 \\
Optimized & 17994 & 11866 & 1.52 & 100.00 \\
\hline
\end{tabular}

existence of the $\mathrm{O}-\mathrm{H}$ stretching bond. The weak $\mathrm{C}-\mathrm{H}$ stretching vibration peak at $2932 \mathrm{~cm}^{-1}$ is the characteristic absorption peak of carbohydrates, indicating that methylene is contained, and the asymmetric $\mathrm{C}=\mathrm{O}$ stretching vibration peak at $1648 \mathrm{~cm}^{-1}$ indicates that the sample has a pyran ring structure. The band at $1730.0 \mathrm{~cm}^{-1}$ indicates the presence of methyl ester groups, while the band at $1650 \mathrm{~cm}^{-1}$ indicates the presence of aminoacyl groups [30]. The strong absorption peak between $1500 \mathrm{~cm}^{-1}$ and $1700 \mathrm{~cm}-1$ is the characteristic absorption peak of polygalactose [31]. The peak at $1100 \mathrm{~cm}^{-1}$ was superposed by angular vibration absorption peaks of alcohol hydroxyl$\mathrm{OH}$ and $\mathrm{C}-\mathrm{O}$ stretching vibration. The absorption peak of the optimized group at $902 \mathrm{~cm}^{-1}$ means that it has a $\beta$ glycosidic bond structure. Also, in the control group, the characteristic absorption peak of the a-glycosidic bond is at $850 \mathrm{~cm}^{-1}$. 


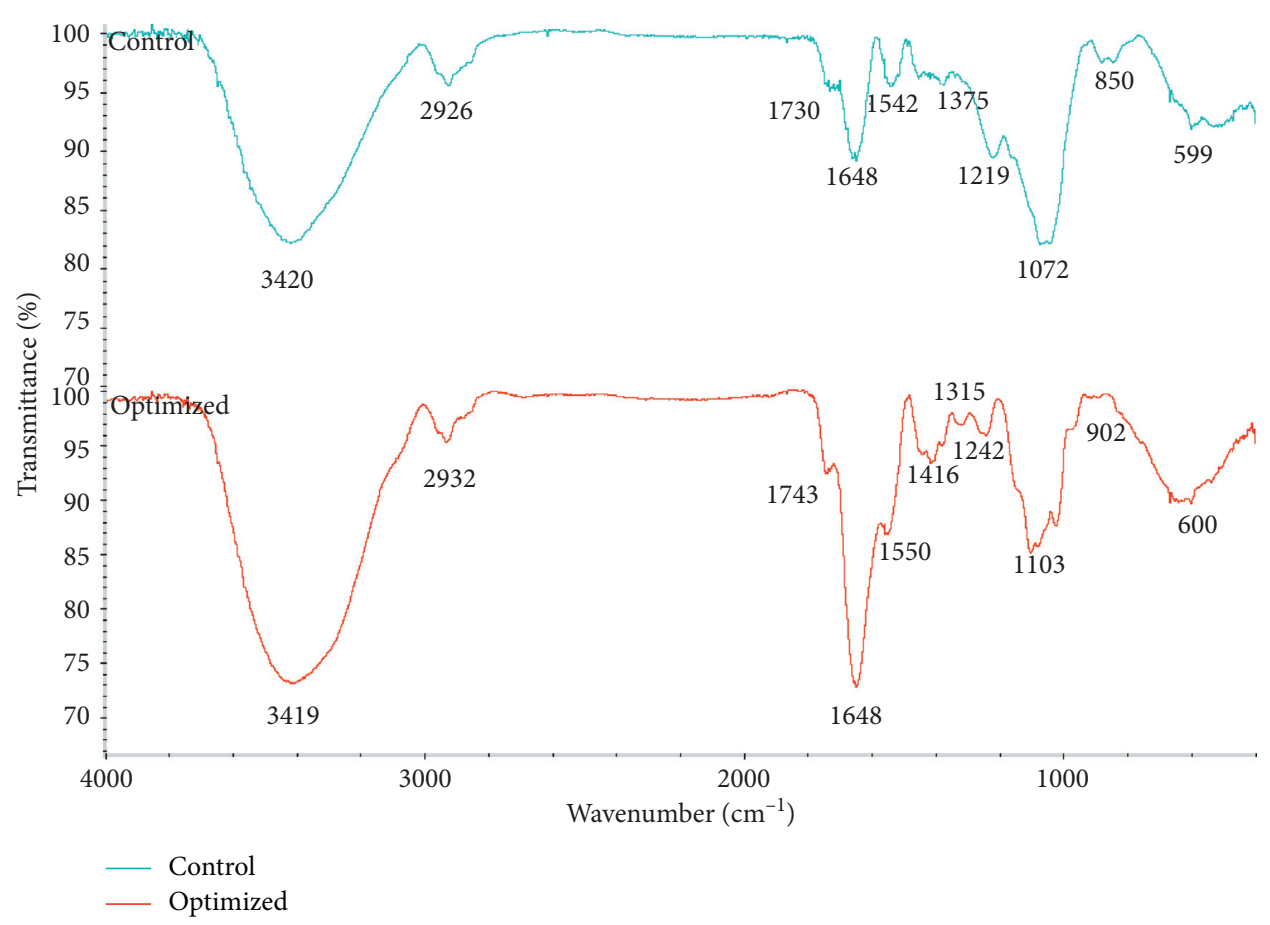

FIgURE 7: FT-IR spectra of FTP in the control and optimized group.

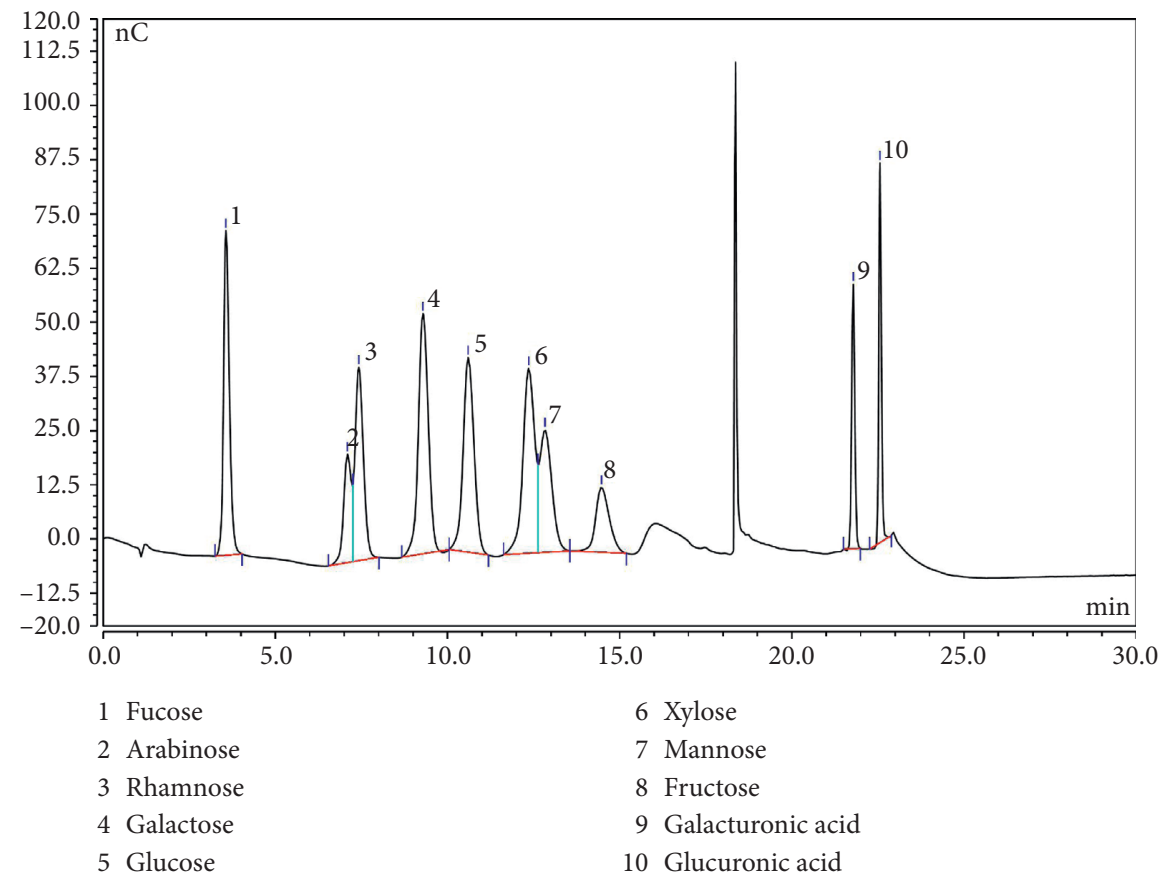

(a)

FIgURe 8: Continued. 


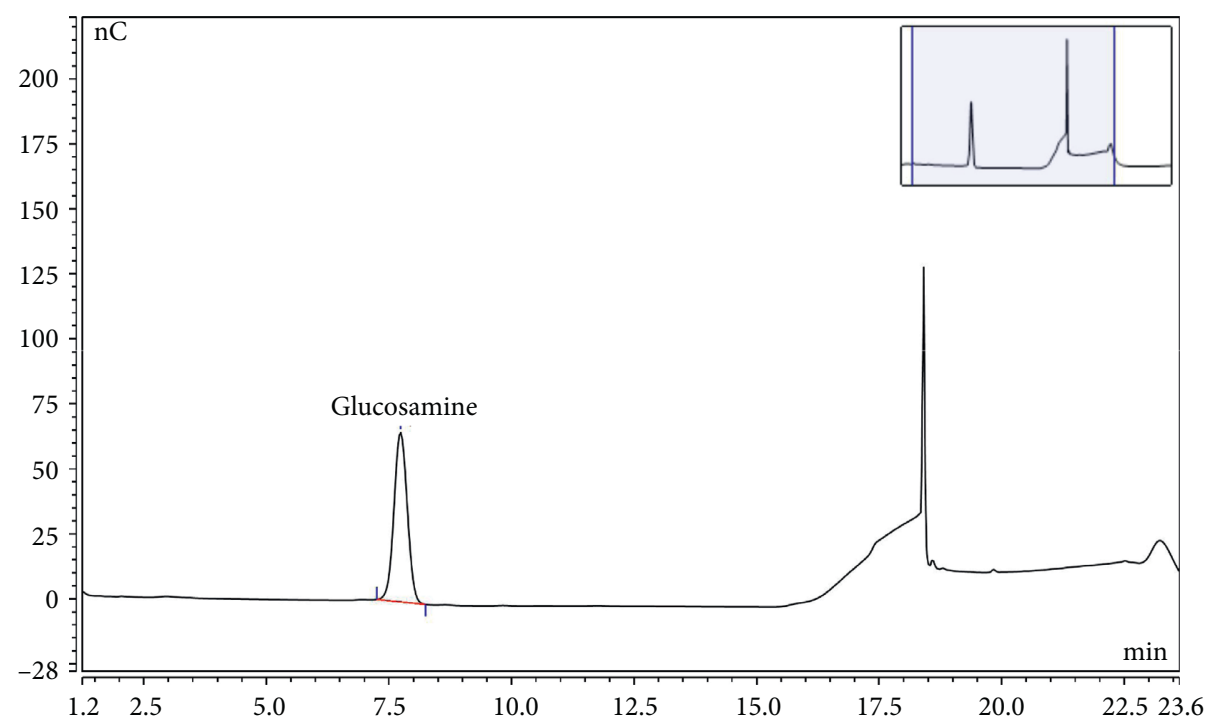

(b)

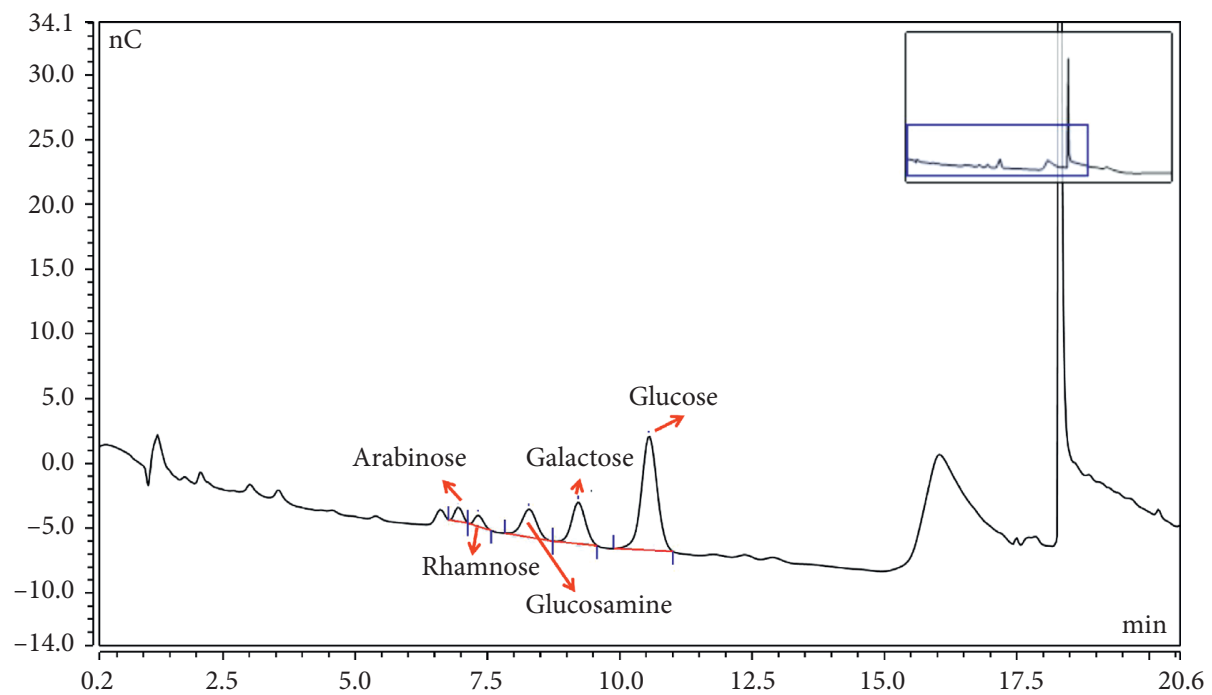

(c)

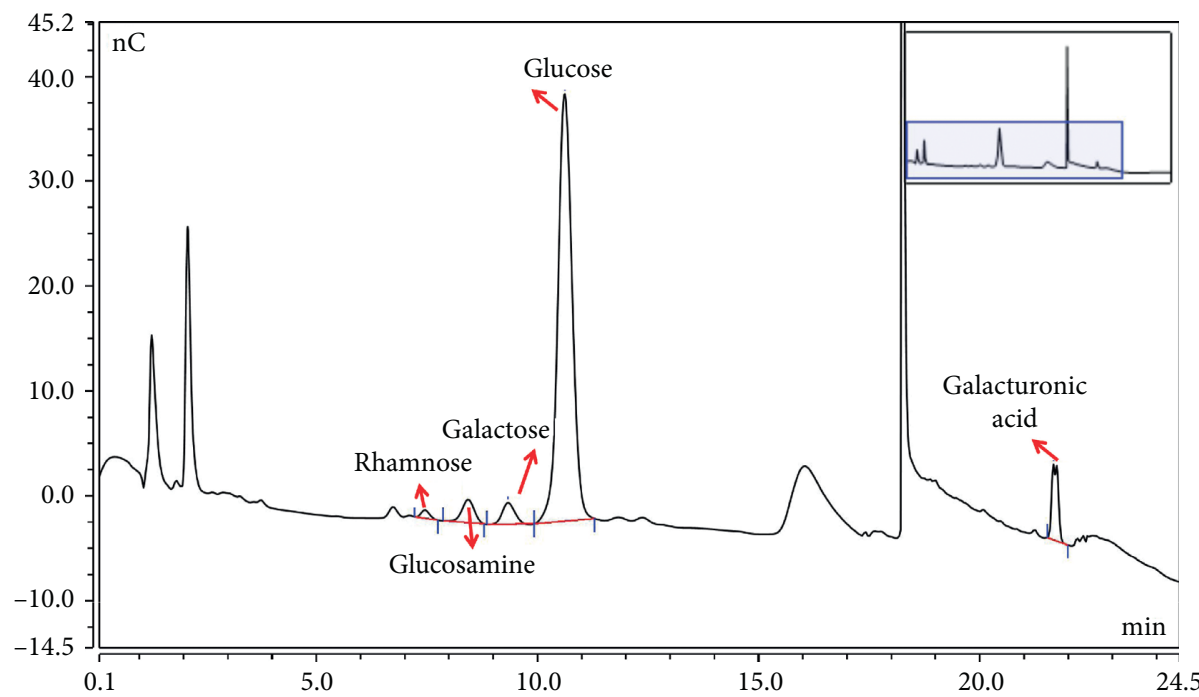

(d)

FIGURE 8: Monosaccharide composition of FTP. (a) 10 standard monosaccharide profiles. (b) Chromatogram of glucosamine standard. (c) The monosaccharide composition of the control group. (d) The monosaccharide composition of the optimized group. 
3.11. Monosaccharide Composition Change. The monosaccharide composition of FTP in the control and optimized group is shown in Figure 8. The monosaccharides in the control group were arabinose, rhamnose, glucosamine, galactose, and glucose. The monosaccharide composition of the optimization group was glucosamine, rhamnose, galactose, glucose, and galacturonic acid. Compared with the control group, the specificity of the optimized group was manifested in the presence of a galacturonic acid structure and the absence of arabinose, which was correlated with the increase of acid polysaccharide content in the optimized group (Figure 5). The monosaccharide types in the control group and the optimized group were similar, but the proportion was different. The content of glucosamine and galactose is decreased, and that of glucosamine and glucuronic acid is increased. This result implies that the change of the culture medium formula can affect the primary structure of FTP.

\section{Conclusions and Prospect}

The optimized medium combination of Tremella GT2\# was determined to be potato extract $22.01 \%$, glucose $29.38 \mathrm{~g} / \mathrm{L}$, peptone $2.61 \mathrm{~g} / \mathrm{L}, \mathrm{KH}_{2} \mathrm{PO}_{4} 3 \mathrm{~g} / \mathrm{L}, \mathrm{MgSO}_{4} \cdot 7 \mathrm{H}_{2} \mathrm{O} 1.5 \mathrm{~g} / \mathrm{L}$, and $\mathrm{Vb}_{1} 7 \mathrm{mg} / \mathrm{L}$. The optimized comprehensive potato medium has high yield of FTP and a high utilization rate of reducing sugar to reduce resource waste. Compared with the existing level of FTP $(4 \mathrm{~g} / \mathrm{L})$, the production was improved to $12.36 \mathrm{~g} / \mathrm{L}[12-14]$. Also, the fermentation period was reduced from $120 \mathrm{~h}$ to $72 \mathrm{~h}$. The increase in production and the shortening of the fermentation cycle were an important breakthrough for the industrialization of FTP. Potato extract, glucose, and peptone were the factors that have the greatest impact on the productivity of FTPs. In addition, the composition and structure of FTPs have also been significantly affected. The FTPs obtained after optimization have a higher acidic polysaccharide content $(66.19 \%)$ and a lower protein content $(1.17 \%)$. The molecular weight and functional groups of FTP did not change significantly before and after optimization, but the composition of monosaccharides changed, and the configuration of polysaccharides changed from $a$-configuration to $\beta$ configuration.

Previous studies have proved that acidic Tremella polysaccharide has a variety of biological activities, including immune activity [32], moisture retention [8], and antiobesity activity [33]. Therefore, the optimized medium is of great significance in the production of active Tremella polysaccharide and fermentation-enabled wellness foods and functional fermented foods [34]. Regarding the reasons for the changes in the FTP structure, a detailed research plan will be proposed in the future work. In addition, the relationship between the biological activity of FTP and its structure should also receive further attention.

\section{Data Availability}

The data used to support the findings of this study are included within the article.

\section{Disclosure}

Xia Ma, Meng Yang, and Yan He are the co-first authors.

\section{Conflicts of Interest}

The authors declare that there are no conflicts of interest regarding the publication of this paper.

\section{Authors' Contributions}

All the authors have made substantive intellectual contributions to the study and given approval to the final version of the manuscript. Xia Ma and Meng Yang mainly contributed to the study design, manuscript revision, experimental studies, and statistical analysis; Yan He contributed to the supervision and project administration; Chengliang $\mathrm{Li}$ contributed to the funding acquisition; and Chuntao Zhai polished and revised the first draft.

\section{Acknowledgments}

The authors gratefully acknowledge the financial support from the Open Project Program of the State Key Laboratory of Dairy Biotechnology (No. SKLDB2013-09), the Open Project Program of the National R \& D Center for Edible Fungus Processing Technology (20200110), and the Shanghai Science and Technology Commission Project (18495810900).

\section{References}

[1] R. U. A. N. Yang, L. I. Hong, L. Pu et al., "Tremella fuciformis polysaccharides attenuate oxidative stress and inflammation in macrophages through miR-155," Analytical Cellular Pathology, vol. 2018, pp. 8316-8324, Article ID 5762371, 2018.

[2] Z.-W. Shi, Y. Liu, Y. Xu et al., "Tremella Polysaccharides attenuated sepsis through inhibiting abnormal CD4 + CD25high regulatory T cells in mice," Cellular Immunology, vol. 288, no. 1-2, pp. 60-65, 2014.

[3] Y. Zhou, X. Chen, R. Yi et al., "Immunomodulatory effect of tremella polysaccharides against cyclophosphamide-induced immunosuppression in mice," Molecules, vol. 23, no. 2, p. 239, 2018.

[4] X. Shi, W. Wei, and N. Wang, "Tremella polysaccharides inhibit cellular apoptosis and autophagy induced by Pseudomonasï $i^{1 / 2}$ aeruginosa lipopolysaccharide in A549 cells through sirtuin 1 activation," Oncology Letters, vol. 15, pp. 9609-9616, 2018.

[5] J. Yan, L. Zhu, Y. Qu et al., "Analyses of active antioxidant polysaccharides from four edible mushrooms," International Journal of Biological Macromolecules, vol. 123, no. 3, pp. 945-956, 2019.

[6] X. Chen, Q. Tang, Y. Chen, W. Wang, and S. Li, "Simultaneous extraction of polysaccharides from poria cocos by ultrasonic technique and its inhibitory activities against oxidative injury in rats with cervical cancer," Carbohydrate Polymers, vol. 79, no. 2, pp. 409-413, 2010.

[7] E. Bach, S. Costa, H. Oliveira et al., "Use of Polysaccharide extracted from Tremella fuciformis Berk for control diabetes induced in rats," Emirates Journal of Food and Agriculture, vol. 27, no. 7, pp. 585-591, 2015. 
[8] C.-P. Lin and S.-Y. Tsai, "Differences in the moisture capacity and thermal stability of tremella fuciformis polysaccharides obtained by various drying processes," Molecules, vol. 24, no. 15, p. 2856, 2019.

[9] A. T.-B. Nguyen, M. Nigen, L. Jimenez, H. Ait-Abderrahim, S. Marchesseau, and L. Picart-Palmade, "Performances of different protocols for exocellular polysaccharides extraction from milk acid gels: application to yogurt," Food Chemistry, vol. 239, pp. 742-750, 2018.

[10] Li Zhang, Study on the Industrialized Cultivation Technique of Tremella, Shanxi Agricultural University, Shanxi, China, 2016.

[11] Z. Lin, J. Ma, B. Chai et al., "Pharmacological study on Tremella: preliminary study on fermentation liquid and polysaccharide of Tremella fuciformis," Journal of Traditional Chinese Medicine, vol. 3, pp. 56-58, 1981.

[12] Qilu University of Technology, Method For Extracting Tremella Polysaccharide And Tremella Protein: cn 102876750 a, Qilu University of Technology, Jinan, China, 2013.

[13] China University of Petroleum, Method For Fermenting And Producing Tremella Polysaccharides By Adopting Constant Ph Feeding Strategy: cn102041285b, China University of Petroleum, Beijing, China, 2013.

[14] China University of Petroleum, Method For Fermenting To Produce Tremellan By Staged Ph Value Control Policy : cn 102041286a, China University of Petroleum, Beijing, China, 2011.

[15] R. Wang, J. Yan, X. Wu et al., "Effects of submerged fermentation on acidic polysaccharides in Tremella fuciformis mycelia," Food Science, vol. 21, pp. 170-172, 2009.

[16] D. Wu, J. Zhang, and X. Yang, "Study on submerged fermentation conditions of tremella fuciformis," Food Science, vol. 23, no. 1, pp. 64-69, 2002.

[17] Y. Yuan, L. Shan, W. U. Yao et al., "Effect of culture conditions on the biomass and exopolysaccharide production by mycelium of Tremella fuciformis," Science and Technology of Food Industry, vol. 2, pp. 242-244, 2010.

[18] L. Ruan, D. Su, S. Shan et al., "Effects of different conditions on the yield of polysaccharides and spores from tremella fuciformis[J]," Edible Fungi of China, vol. 34, no. 3, pp. 47-50, 2015.

[19] Y. Guo, X. Ye, B. Gan et al., "Study on the mycelial germination of Tremella fuciformis spores on different media," Southwest China Journal of Agricultural Sciences, vol. 25, pp. 1794-1797, 2012.

[20] S. Ukai, K. Hirose, T. Kiho et al., "Antitumor activity on sarcoma 180 of the polysaccharides from tremella fuciformis BERK," Chemical \& Pharmaceutical Bulletin, vol. 20, no. 10, pp. 2293-2294, 1972.

[21] Y. Zhu, "Optimization method of microbial medium and its OPTI Optimization Software," Foreign Journal of Medical Antibiotics, vol. 20, pp. 58-61, 1999.

[22] Shanghai Institute of Technology, Method for extracting Tremella polysaccharide from fermentation broth: CN201910265408, Shanghai Institute of Technology, Shanghai, China, 2019.

[23] H.-F. Zhang, L.-L. Niu, X.-H. Yang, and L. Li, “Analysis of water-soluble polysaccharides in an edible medicinal plant epimedium: method development, validation, and application," Journal of Aoac International, vol. 97, no. 3, pp. 784-790, 2014.

[24] J. Wang, S. Zhang, B. Yang et al., "Application of 3, 5-dinitrosalicyiic acid(dns)method to test the reducing sugar and water-soluble total sugar content in sugarcane internodes," Sugarcane and Canesugar, vol. 5, pp. 45-49, 2008.
[25] M. M. Bradford, "A rapid and sensitive method for the quantitation of microgram quantities of protein utilizing the principle of protein-dye binding," Analytical Biochemistry, vol. 72, pp. 248-254, 2007.

[26] J. Xie, L. Zou, X. Luo et al., "Structural characterization and immunomodulating activities of a novel polysaccharide from nervilia fordii," International Journal of Biological Macromolecules, vol. 114, pp. 520-528, 2018.

[27] P. Conte and A. Piccolo, "High pressure size exclusion chromatography (HPSEC) of humic substances: molecular sizes, analytical parameters, and column performance," Chemosphere, vol. 38, pp. 520-528, 1999.

[28] J.-H. Xie, M.-Y. Shen, S.-P. Nie, X. Liu, H. Zhang, and M.-Y. Xie, "Analysis of monosaccharide composition of Cyclocarya paliurus polysaccharide with anion exchange chromatography," Carbohydrate Polymers, vol. 98, no. 1, pp. 976-981, 2013.

[29] D.-T. Wu, Y. Deng, J. Zhao, and S.-P. Li, "Molecular characterization of branched polysaccharides from Tremella fuciformis by asymmetrical flow field-flow fractionation and size exclusion chromatography," Journal of Separation Science, vol. 40, no. 21, pp. 4272-4280, 2017.

[30] J.-Y. Qian, W. Chen, W.-M. Zhang, and H. Zhang, "Adulteration identification of some fungal polysaccharides with SEM, XRD, IR and optical rotation: a primary approach," Carbohydrate Polymers, vol. 78, no. 3, pp. 620-625, 2009.

[31] M. Kozarski, A. Klaus, M. Niksic, D. Jakovljevic, P. F. G. Helsper, and L. J. L. D. Van Griensven, “Antioxidative and immunomodulating activities of polysaccharide extracts of the medicinal mushrooms agaricus bisporus, Agaricus brasiliensis, ganoderma lucidum and phellinus linteus," Food Chemistry, vol. 129, no. 4, pp. 1667-1675, 2011.

[32] X. Shi, W. Wei, and N. Wang, "Tremella polysaccharides inhibit cellular apoptosis and autophagy induced by Pseudomonas aeruginosa lipopolysaccharide in A549 cells through sirtuin 1 activation," Oncology Letters, vol. 15, no. 6, pp. 9609-9616, 2018.

[33] C. Xu, J. Y. Diao, and S. M. Wang, "Recent progress in pharmacological studies of polysaccharide from tremella fuciformis berk," Pharmacy Today, vol. 28, no. 3, pp. 207-210, 2018.

[34] H. Xiang, D. Sun-Waterhouse, G. I. N. Waterhouse, C. Cui, and Z. Ruan, "Fermentation-enabled wellness foods: a fresh perspective," Food Science and Human Wellness, vol. 8, no. 3, pp. 203-243, 2019. 